Meeting Summary

\title{
Nonclinical and quality assessment of cell therapy products: Report on the 4th Asia Partnership Conference of Regenerative Medicine, April 15, 2021
} \author{
Takeshi Watanabe $^{9}$, Keiji Yoshimura ${ }^{12}$, Masayuki Nomura ${ }^{13}$ \\ ${ }^{1}$ Novartis Pharma K.K., Tokyo, Japan \\ ${ }^{2}$ Astellas Pharma Inc., Tokyo, Japan \\ ${ }^{3}$ Sumitomo Dainippon Pharma Co., Ltd., Kobe, Japan \\ ${ }^{4}$ Strategic Center for Regenerative Medicine, Inha University College of Medicine, Incheon, South Korea \\ ${ }^{5}$ Acepodia Inc., Taipei, Taipei, Taiwan \\ ${ }^{6}$ Stempeutics Research, Bangalore, India \\ ${ }^{7}$ SCM Lifescience Inc., Incheon, South Korea \\ ${ }^{8}$ Daiichi Sankyo Co., Ltd., Tokyo, Japan \\ ${ }^{9}$ Takeda Pharmaceutical Company Limited, Fujisawa, Japan \\ ${ }^{10}$ EMO Biomedicine, Taipei, Taiwan \\ ${ }^{11}$ Astellas Pharma Inc., Tsukuba, Japan \\ ${ }^{12}$ Japan Tissue Engineering Co., Ltd., Aichi, Japan \\ ${ }^{13}$ Asahi Kasei Corporation, Tokyo, Japan
}

Tomohiro Yoneda ${ }^{1, \dagger, *}$, Toshimitsu Tanaka ${ }^{2, \dagger, * *}$, Kiyoko Bando ${ }^{3}$, Byung Hyune Choi ${ }^{4}$, Ryan Chang ${ }^{5}$, Yukari Fujiwara ${ }^{1}$, Pawan Kumar Gupta ${ }^{6}$, Dong-sik Ham ${ }^{7}$, Hiroshi Karasawa ${ }^{8}$, Shinobu Kuwae ${ }^{9}$, Shing-mou Lee ${ }^{10}$, Yuu Moriya ${ }^{9}$, Koji Takakura ${ }^{11}$, Yoshie Tsurumaki ${ }^{1}$,

\section{A R T I C L E I N F O}

\section{Article History:}

Received 31 October 2021

Accepted 21 January 2022

\section{Keywords:}

APACRM

Asia

cell therapy product

nonclinical

quality

regulatory guideline

\begin{abstract}
A B S T R A C T
The 4th Asia Partnership Conference of Regenerative Medicine (APACRM) was held online on April 15, 2021, to promote regulatory harmonization of regenerative medicine products throughout Asia. Recognizing domestic regulatory guidelines within each country and region, and their underpinning rationales, is an important initial step toward a convergence of regulations. The 4th APACRM consisted of an open dialog with regulatory agencies regarding nonclinical and quality settings for cell therapy products (CTPS) through industry presentations and panel discussions with regulatory agencies. The latest updates on regenerative medicine fields in each country and region, and specific regulatory schematics in Japan, were also introduced. The objective of this paper is to summarize the proceedings of the 4th APACRM for public dissemination and to foster further discussion in the future.

(C) 2022 International Society for Cell \& Gene Therapy. Published by Elsevier Inc. This is an open access article under the CC BY-NC-ND license (http://creativecommons.org/licenses/by-nc-nd/4.0/)
\end{abstract}

\section{Introduction}

The Asia Partnership Conference of Regenerative Medicine (APACRM) was established in 2018 with the aim of optimizing, and eventually harmonizing, regulations of regenerative medicine (RM) among Asian countries and regions, with the leading industry

\footnotetext{
* Corresponding author. Translational Medicine, Novartis Institutes for Biomedical Research, Novartis Pharma K.K., Toranomon Hills Mori Tower, 1-23-1, Toranomon, Minato-ku, Tokyo, Japan

** Co-Corresponding author. CMC Regulatory Affairs, Regulatory Affairs, Astellas Pharma Inc., 2-5-1, Nihonbashi-Honcho, Chuo-Ku, Tokyo, Japan

E-mail address: tomohiro.yoneda@novartis.com (T. Yoneda).

$\dagger$ T. Yoneda and T. Tanaka contributed equally to this work.
}

associations for RM as contributing members of the forum (Figure 1). The broader mission of the APACRM is to support the development and delivery of high-quality RM products to all patients in Asia; to this end, it is important to promote regulatory alignment.

The 4th APACRM meeting was held online April 15, 2021, assembling 50 presenters and panelists, in addition to 150 viewing audiences from India, Singapore, China, Korea, Taiwan, Japan, Indonesia, Malaysia, Myanmar, the Philippines, Thailand and Vietnam. All participants contributed to the valuable discussions corresponding with the agenda. Notably, health authority regulators from each country and region joined the discussion as panelists and commenting participants.

This proceedings paper summarizes the content of the 4th APACRM, with particular focus given to the dialog with regulators 


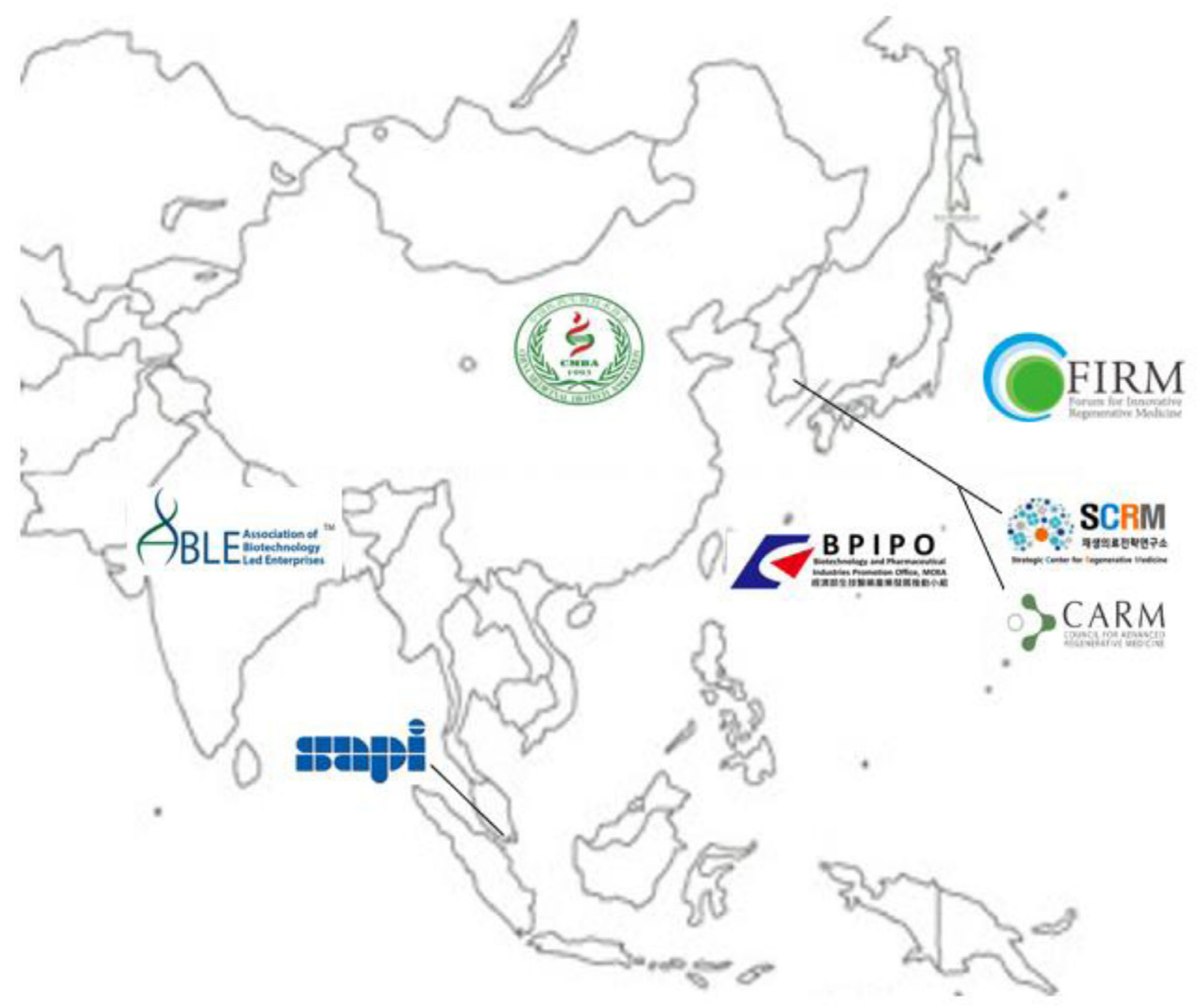

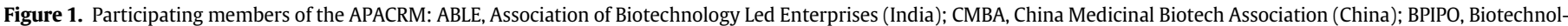

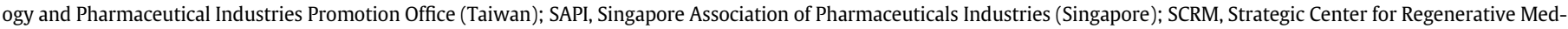
icine (Korea); CARM, The Council for Advanced Regenerative Medicine (Korea); FIRM, Forum for Innovative Regenerative Medicine (Japan).

based on the survey results of two working groups (WGs): WG1 for nonclinical and WG2 for quality assessments. Views were exchanged in the panel discussion to better understand the degree of regulatory alignment among participating Asian countries and regions.

\section{Program and Session Summaries}

The 4th APACRM consisted of four sessions (Table 1). Two key sessions regarding the WG activities are briefly described below, and further details are provided in Working Group 1: Nonclinical Panel Discussion and Working Group 2: Quality Panel Discussion.

\section{Session 1: Update on regenerative medicine from each industrial} association

In the first session, "Update on Regenerative Medicine from each participating industry association," an array of topics pertaining to $\mathrm{RM}$ in each country and region were shared. Approved regenerative medicine products for each country and region are listed in Table 2.

Yoshitsugu Shitaka, a presenter of Forum for Innovative Regenerative Medicine (FIRM) from Japan, provided an update on cell and gene therapy product development and regulations in Japan. Four products had been approved within the previous year, bringing the total number up to 11 as of March 2021. Eight of these products have been fully approved, while three are conditional and time-limited approvals. The SAKIGAKE designation system, which began in 2015 as a trial operation to expedite the review of innovative medicines, was enacted as law in 2020.

Alex Y.P. Tsui, a presenter from the China Medicinal Biotech Association (CMBA), shared the current national regulation of RM products in China, where the Pharmaceutical Administration Law had been amended in 2019. Two key actions were taken under the new law. First, regulators indicated their support for pharmaceutical innovation aimed at curing human diseases, prioritizing the development of new drugs and therapeutics capable of (i) treating life-threatening and rare diseases based on novel mechanisms of action (MOA), and (ii) ameliorating diseases via multitargeting and systemic intervention. Second, regulators were trying to strengthen the process control and management of new drug development and clinical trials, as well as the review and approval process. To this end, regulators provided greater opportunities for mentoring and consulting within the industry, thus establishing stronger lines of communication. Indeed, efforts have been made with increasing frequency for their mentoring and consulting under the newly published regulatory and policy documents. Other topics presented included ongoing clinical trials of stem cell and chimeric antigen receptor T cell (CAR-T) products and examples of industry standards established by cooperation among participating associations.

Bryan Choi, a presenter from the Strategic Center for Regenerative Medicine (SCRM) and Council for Advanced Regenerative Medicine (CARM) in Korea, provided an update on product developments and regulations in Korea. Sixteen products had been marketapproved by 2020, and the number of new clinical trials, including those with gene therapies and gene-modified cells, have been increasing gradually. Multiple cases of immune cell therapies under commercial development are expected to enter clinical trials in the near future. Most RM companies in Korea develop cell therapies, with several companies in the gene therapy or gene-modified cell therapy sector. Recently, several companies have been attempting to expand their business internationally. The Advanced Regenerative-Bio Act was passed by Congress in August 2019 (enacted 1 year later), and the corresponding RM regulatory process consists of two tracks. One is the industry-sponsored trials for advanced biopharmaceuticals under the control of the Ministry of Food and Drug 
Table 1

Meeting program of the 4th APACRM on April 15, 2021.

\begin{tabular}{|c|c|c|}
\hline Time (JST) & Session & Presenter \\
\hline 13:00-13:03 & Opening remarks & Ken-ichiro Hata, FIRM (Japan) \\
\hline 13:03-13:10 & Introduction & Masayuki Nomura, FIRM (Japan) \\
\hline \multirow[t]{6}{*}{$13: 10-14: 10$} & \multicolumn{2}{|c|}{ Session 1: Update on regenerative medicine from each industrial association } \\
\hline & 10 -min presentations from each country and region & Yoshitsugu Shitaka, FIRM (Japan) \\
\hline & & Tsui Yat Ping Alex, CMBA (China) \\
\hline & & Bryan Choi, SCRM (Korea) \\
\hline & & Kum Cheun Wong, SAPI (Singapore) \\
\hline & & Shinn-Zong Lin, BPIPO (Taiwan) \\
\hline \multirow[t]{3}{*}{$14: 10-15: 40$} & Session 2: Working group 1 (WG1) activity & \\
\hline & Presentation & Tomohiro Yoneda, WG1 (Japan) \\
\hline & Panel discussion: pharmacology, CKBD, toxicity, tumorigenicity & Facilitator: WG1 members Panelist: Regulatory agencies \\
\hline $15: 40-15: 50$ & Break & \\
\hline \multirow[t]{3}{*}{$15: 50-17: 05$} & Session 3: Working group 2 (WG2) activity & \\
\hline & Latest information sharing & Yoji Sato, NIHS (Japan) \\
\hline & Presentation & Toshimitsu Tanaka, WG2 (Japan) Shing-Mou Lee, WG2 (Taiwan) \\
\hline \multirow[t]{3}{*}{$17: 05-17: 45$} & Session 4: Thematic lecture & \\
\hline & Early approval system in Japan & Keiji Yoshimura, FIRM (Japan) \\
\hline & Price and reimbursement system in Japan & \\
\hline \multirow[t]{4}{*}{$17: 45-18: 10$} & Introduction and exchange opinions for future activities & \\
\hline & WG1 introduction & Tomohiro Yoneda, WG1 (Japan) \\
\hline & WG2 introduction & Toshimitsu Tanaka, WG2 (Japan) \\
\hline & Others (exchange opinions) & Yoshie Tsurumaki, FIRM (Japan) \\
\hline $18: 10-18: 15$ & Closing remarks & Kunihiko Suzuki, FIRM (Japan) \\
\hline
\end{tabular}

Safety (MFDS); and the other is for research trials of RMs under the supervision of the Ministry of Health and Welfare (MOHW). CARM has been an active participant in discussions of the enactment and operation of the act.

Wong Kum Cheun from the Singapore Association of Pharmaceuticals Industries (SAPI) presented on the current national cell and gene product regulations. The Health Sciences Authority (HSA) introduced a new law regulating cell, tissue and gene therapeutic products (CTGTP) under the Health Products Act, placing them into one of two classes. Class 1 is categorized as low risk; for example, minimally manipulated bone marrow reimplanted for homologous use. Class 2 contains higher-risk products; for example, gene-modified cells, cells grown on scaffolds, culture expanded cells, or therapeutic gene- and genome-based products. During clinical trials, class 1 is regulated by the Human Biomedical Research Act of the Ministry of Health, and class 2 products are required to apply for a clinical trial authorization or to submit a clinical trial notification to the HSA.

Dr. Pawan Kumar Gupta of Association of Biotechnology Led Enterprises (ABLE) in India presented on the national regulatory framework and pathways for RM, where several guidelines had been issued by regulatory agencies. According to the New Drugs and Clinical Trials Rules 2019 issued by the Central Drugs Standard Control Organization (CDSCO), any stem cell-derived products, gene therapeutic products or xenografts intended for use will always remain a new drug. Although the final guidelines or rules are pending, the definition of stem cell-derived products was clarified by CDSCO in 2019. Notably, minimal manipulation of cells cannot be considered a drug. There are four approved cell therapy products (CTPs), and the first clinical trial of CAR-T products is to be initiated soon. According to the National Guidelines for Stem Cell Research issued by the Indian Council of Medical Research (ICMR) and Department of Biotechnology (DBT) in 2017, all stem cell therapies, save for bone marrow transplants in approved indications, must be conducted as a clinical trial and registered with the Clinical Trial Registry of India.

Shinn-Zong Lin, a presenter of Biotechnology and Pharmaceutical Industries Promotion Office (BPIPO) from Taiwan, spoke on national RM development and provided an overview of the local health care system. Taiwan has a high-quality health care system, well-trained physicians and affordable healthcare under the public health insurance system, where the cost of surgery in Taiwan can be less than one-fifth of that in Western countries. Taiwan adopted a dualtrack management system of RM, treating products as either medicinal or medical. Under the Administrative Regulation on Specific Cellular Therapeutic Technology, cell therapy technologies can be proposed to the Regenerative Medicine Advisory Council and then sent for review to the Specific Medical Technology Committee organized by the Ministry of Health and Welfare. Upon approval, the technology can obtain a conditional, 3-year license, with renewal subject to regulatory reviews on safety and efficacy. In total, $>40$ hospitals and 73 items have already been approved for use nationwide. Many of the approved indications are solid cancers. Notably, one difficulty mentioned regards the high cost of treatment, since Taiwanese residents are accustomed to lower medical price systems.

\section{Session 2: Working group 1 activity}

After the presentation of the survey results by WG1 (nonclinical) based on Yoneda et al. [1], a panel discussion with regulatory agencies was conducted, the details of which are described in Working Group 1: Nonclinical Panel Discussion.

\section{Session 3: Working group 2 activity}

After a presentation of the survey results by WG2 (quality) based on Tanaka et al. [2], a panel discussion with regulatory agencies was performed, the details which are presented in Working Group 2: Quality Panel Discussion.

Dr. Yoji Sato, the Head of the Division of Cell-Based Therapeutic Products for Japan National Institute of Health Sciences, shared the key points of three national guideline documents, either published or under draft, for ensuring CTP quality and safety by establishing (i) the minimum consensus package of technical requirements, standards and considerations for the quality and safety evaluation of humanderived CTPs, (ii) the points-to-consider document regarding tumorigenicity assessment of CTPs; and (iii) a drafted guidance document on comparability evaluation before and after changes to the CTP manufacturing process. 
Table 2

List of the approved regenerative medicine products in each country and region

\begin{tabular}{|c|c|c|c|c|c|}
\hline Country/region & Product name & Company & Indication & Technologies & Approval year \\
\hline \multirow[t]{5}{*}{ India } & Ossron & $\begin{array}{l}\text { M/s Regenerative Medical } \\
\text { Services }\end{array}$ & Avascular necrosis of hip joint & $\begin{array}{l}\text { Autologous adult live cultured } \\
\text { osteoblast }\end{array}$ & 2017 \\
\hline & Chondron & $\begin{array}{l}\text { M/s Regenerative Medical } \\
\text { Services }\end{array}$ & $\begin{array}{l}\text { Articular cartilage defects of knee } \\
\text { joint }\end{array}$ & $\begin{array}{l}\text { Autologous adult live cultured } \\
\text { chondrocytes }\end{array}$ & 2017 \\
\hline & Apceden & M/s APAC Biotech & Ovary and lung cancer & $\begin{array}{l}\text { Autologous dendritic cell } \\
\text { immunotherapy }\end{array}$ & 2017 \\
\hline & Stempeucel & M/s Stempeutics Research & $\begin{array}{l}\text { Critical limb ischemia due to Buerg- } \\
\text { er's disease }\end{array}$ & $\begin{array}{l}\text { Bone marrow derived, cultured, } \\
\text { pooled, allogeneic mesenchymal } \\
\text { stromal cells }\end{array}$ & 2017 \\
\hline & Stempeucel & M/s Stempeutics Research & $\begin{array}{l}\text { Critical limb ischemia due athero- } \\
\text { sclerotic peripheral artery disease }\end{array}$ & $\begin{array}{l}\text { Bone marrow derived, cultured, } \\
\text { pooled, allogeneic mesenchymal } \\
\text { stromal cells }\end{array}$ & 2020 \\
\hline Singapore & Kymriah & Novartis Pharma & $\begin{array}{l}\text { B-cell acute lymphoblastic leukemia } \\
\text { (ALL) in children, relapsed/refrac- } \\
\text { tory diffuse large B-cell lymphoma } \\
\text { (DLBCL) }\end{array}$ & Autologous CAR-T targeting CD19 & 2021 \\
\hline \multirow{3}{*}{ China } & Oncorine & Shanghai Sunway Biotech & $\begin{array}{l}\text { Advanced nasopharyngeal carci- } \\
\text { noma, head and neck, liver }\end{array}$ & $\begin{array}{l}\text { Recombinant p53 gene incorporated } \\
\text { adenoviral vector }\end{array}$ & 2019 \\
\hline & Yescarta & $\begin{array}{l}\text { Shanghai Fosun } \\
\text { Pharmaceutical }\end{array}$ & $\begin{array}{l}\text { Relapsed/refractory large B-cell } \\
\text { lymphoma }\end{array}$ & Autologous CAR-T targeting CD19 & 2021 \\
\hline & Carteyva & JW Therapeutics & $\begin{array}{l}\text { Relapsed/refractory large B-cell } \\
\text { lymphoma }\end{array}$ & Autologous CAR-T targeting CD19 & 2021 \\
\hline \multirow[t]{16}{*}{ Korea } & Chondron & Sewoncellontech & Knee cartilage defect & Autologous chondrocyte & 2001 \\
\hline & Holoderm & Tegoscience & Skin burn therapy & Autologous skin keratinocyte & 2002 \\
\hline & Kaloderm & Tegoscience & Skin burn therapy, Diabetic foot ulcer & Allogenic skin keratinocyte & 2005 \\
\hline & Keraheal & MCTT & Skin burn therapy & Autologous skin keratinocyte & 2006 \\
\hline & CreaVax-RCC Inj & Creagene & Metastatic renal cell carcinoma & Autologous dendritic cell & 2007 \\
\hline & Immuncell-LC & Innocell & Hepatoma & Autologous activated lymphocyte & 2007 \\
\hline & RMS ossron & Sewoncellontech & Local osteoblastic palpation & Autologous osteocyte & 2009 \\
\hline & Queen cell & Antrogen & Hypodermic fat loss & Autologous, minimal manipulation & 2010 \\
\hline & Cure skin & Sbiomedics & Acne scar, skin scar & Autologous fibroblast & 2010 \\
\hline & Heaticellgram-AMI & FCB Pharmacell & Acute myocardial infarction & $\begin{array}{l}\text { Autologous bone marrow-derived } \\
\text { MSC }\end{array}$ & 2011 \\
\hline & Cartistem & Medipost & Knee cartilage defect & $\begin{array}{l}\text { Allogenic umbilical cord-derived } \\
\text { MSC }\end{array}$ & 2012 \\
\hline & Neuronata-R & Corestem & ALS (Lou Gehrig's disease) & $\begin{array}{l}\text { Autologous bone marrow-derived } \\
\text { MSC }\end{array}$ & 2014 \\
\hline & Keraheal-allo & Biosolutions & Skin burn therapy & Allogenic skin keratinocyte & 2015 \\
\hline & Rosmir & Tegoscience & Nasojugal groove & Autologous cultured fibroblasts & 2017 \\
\hline & Cartilife & Biosolutions & Knee cartilage defects & $\begin{array}{l}\text { Autologous costal chondrocytes } \\
\text { (microsphere) }\end{array}$ & 2019 \\
\hline & Kymriah & Novartis Pharma & $\begin{array}{l}\text { B-cell ALL in children, relapsed/ } \\
\text { refractory DLBCL }\end{array}$ & Autologous CAR-T targeting CD19 & 2021 \\
\hline \multirow[t]{2}{*}{ Taiwan } & Zolgensma & Novartis Pharma & Spinal muscular atrophy & $\begin{array}{l}\text { Recombinant AAV9 expressing } \\
\text { human SMN protein }\end{array}$ & 2020 \\
\hline & Kymriah & Novartis Pharma & $\begin{array}{l}\text { B-cell ALL in children, relapsed/ } \\
\text { refractory DLBCL }\end{array}$ & Autologous CAR-T targeting CD19 & 2021 \\
\hline \multirow[t]{9}{*}{ Japan } & JACE & $\begin{array}{l}\text { Japan Tissue Engineering (J- } \\
\text { TEC) }\end{array}$ & $\begin{array}{l}\text { Severe burns, giant congenital mela- } \\
\text { nocytic nevi, dystrophic epider- } \\
\text { molysis bullosa and junctional } \\
\text { epidermolysis bullosa }\end{array}$ & $\begin{array}{l}\text { Autologous epidermal-derived cell } \\
\text { sheet }\end{array}$ & 2007 \\
\hline & JACC & $\mathrm{J}$-TEC & $\begin{array}{l}\text { Traumatic cartilage defect or osteo- } \\
\text { chondritis dissecans of the knee }\end{array}$ & Autologous cartilage-derived tissue & 2012 \\
\hline & Heartsheet & Terumo & $\begin{array}{l}\text { Severe heart failure due to ischemic } \\
\text { heart disease }\end{array}$ & $\begin{array}{l}\text { Autologous skeletal myo- } \\
\text { blast-derived cell sheet }\end{array}$ & $2015^{*}$ \\
\hline & Temcell HS Inj. & JCR Pharma & Acute graft-versus-host disease & $\begin{array}{l}\text { Allogenic bone marrow-derived } \\
\text { MSCs }\end{array}$ & 2015 \\
\hline & Stemirac & Nipro & Spinal cord injury & $\begin{array}{l}\text { Autologous bone marrow-derived } \\
\text { MSCs }\end{array}$ & $2018^{*}$ \\
\hline & Collategene & Anges & $\begin{array}{l}\text { Chronic arterial obstruction } \\
\text { (obstructive arteriosclerosis, } \\
\text { Buerger's disease) }\end{array}$ & $\begin{array}{l}\text { A plasmid DNA encoding human HGF } \\
\text { gene }\end{array}$ & $2019^{*}$ \\
\hline & Kymriah & Novartis pharma & $\begin{array}{l}\text { B-cell ALL in children, relapsed/ } \\
\text { refractory DLBCL }\end{array}$ & Autologous CAR-T targeting CD19 & 2019 \\
\hline & Nepic & J-TEC/NIDEK & Limbal stem cell deficiency & $\begin{array}{l}\text { Autologous corneal limbus-derived } \\
\text { corneal epithelial cell sheet }\end{array}$ & 2020 \\
\hline & Zolgensma & Novartis Pharma & Spinal muscular atrophy & $\begin{array}{l}\text { Recombinant AAV9 expressing } \\
\text { human SMN protein }\end{array}$ & 2020 \\
\hline
\end{tabular}


Table 2 (Continued)

\begin{tabular}{|c|c|c|c|c|c|}
\hline Country/region & Product name & Company & Indication & Technologies & Approval year \\
\hline & Yescarta & Daiichi Sankyo & $\begin{array}{l}\text { Relapsed/refractory large B-cell } \\
\text { lymphoma }\end{array}$ & Autologous CAR-T targeting CD19 & 2021 \\
\hline & Breyanzi & BristolMyers Squibb & $\begin{array}{l}\text { Relapsed/refractory large B-cell } \\
\text { lymphoma }\end{array}$ & Autologous CAR-T targeting CD19 & 2021 \\
\hline & Ocural & $\mathrm{J}-\mathrm{TEC}$ & Limbal stem cell deficiency & $\begin{array}{l}\text { Autologous oral mucosa-derived } \\
\text { epithelial cell sheet }\end{array}$ & 2021 \\
\hline & Delitact & Daiichi Sankyo & Malignant glioma & Oncolytic virus G47 delta & 2021 \\
\hline
\end{tabular}

The approved regenerative medicine products as of December 31, 2021, are listed.

* Conditional/time-limited.

\section{Session 4: Thematic lecture}

Keiji Yoshimura, a presenter of FIRM, introduced the early approval system, as well as the price and reimbursement (P\&R) scheme for RM products in Japan that fall under the Pharmaceuticals, Medical Devices and Other Therapeutic Products Act (PMD Act) and are based on the Japanese health insurance system (described below).

\section{Early approval system in Japan}

Under the PMD Act, sponsors must submit an approval application, and in principle, product safety and efficacy are confirmed before marketing (i.e., full market approval); however, in the case of the RM products, it is possible that the inherent heterogeneity of product quality derived from living cells will make such confirmations relatively difficult. Accordingly, RM products can be given "conditional and time-limited marketing authorization" if the product meets certain requirements, including the display of nonuniform characteristics, confirmation of safety, and predicted efficacy (or effectiveness). At the time of the conference, 11 RM products, including nine human cellular/tissue-based and two gene therapy products, had been approved in Japan. Among them, three products had been granted conditional and time-limited approval, although information on these issues is limited by the small number of cases. These conditional products should be used only in appropriate medical institutions, by physicians with adequate experience and sufficient knowledge of the indications and medical techniques, including cell/ tissue collection, and the transplantation/injection of RM products. In addition, the efficacy (or effectiveness), and further safety of these products must be confirmed by postmarketing evaluations of all patients until re-application for full market approval. For more information, the review reports are made publicly available on the Pharmaceuticals and Medical Devices Agency (PMDA) website [3]. In this lecture, the Orphan and SAKIGAKE Designation Systems were also introduced as additional schemes for accelerating research and development and approval of pharmaceuticals, medical devices and RM products in Japan.

\section{PER system for RM products in Japan}

Public P\&R decisions for pharmaceuticals, medical devices and RM products are made at the national level by the Ministry of Health, Labour and Welfare (MHLW). There is no specific pricing rule for RM products in Japan; thus, pharmaceutical or medical device pricing will be applied based on each RM product's characteristics. Thus far, the price determination of pharmaceutical-like RM products, such as cell suspensions, tends to be based on the pricing rule for pharmaceuticals, whereas that of medical device-like RM products, such as cell sheets, tends to be based on the pricing rule of medical devices. In both cases, pricing will be considered by either the cost-comparison method, by comparison to a similar product, or the cost-plus method based on the cost of the product's components. With RM products, the cost-plus method has most often been applied, as no comparable products exist. In practice, RM product prices depend on their various features and characteristics, and FIRM has been working with several stakeholders to develop specific rules for appropriately reflecting these distinct characteristics monetarily.

\section{Working Group 1: Nonclinical Panel Discussion}

Introduction to panel discussion

WG1 focused on the investigation of nonclinical assessments required for entering clinical studies of CTPs in Asian countries and regions from an industry viewpoint. WG1 employed a case-study approach, using a virtual MSC-based CTP as a model product (Table 3). A questionnaire survey of the required nonclinical assessments in each country and region for investigational new drug (IND) submission was conducted, regarding aspects of pharmacology, cellular kinetics (CK), biodistribution (BD), general toxicology and tumorigenicity. Each respondent (India, China, Korea, Taiwan and Japan) in WG1 completed the questionnaire based on local regulatory guidelines and their practical experiences in the interactions with regulatory agencies. Comparisons were made to identify any national or regional similarities and differences regarding the nonclinical assessments required for the IND package, and the rationales behind these traits (Figure 2).

Regulatory agency panel discussion (India, Singapore, Korea, Taiwan and Japan)

After the industry presentation, WG1 proceeded with a panel discussion comprised of regulatory agencies and was classified into three sessions: (1) pharmacology and cellular kinetics and biodistribution (CKBD), (2) general toxicology and (3) tumorigenicity. Table 4

Table 3

Virtual CTP profiles.

\begin{tabular}{ll}
\hline Product profile & Virtual model: MSC-based product \\
\hline Donor type & Allogeneic \\
Development phase & First in human \\
Cell source & Adipose tissue-based MSCs \\
Proliferation activity & Low \\
Mechanism of action & Immunosuppressive effects mediated by \\
& cellular secretions \\
Indication & Rheumatoid arthritis (adults) \\
Clinical administration route & Local (intra-articular) \\
Clinical administration cell number & Low: $1 \times 10^{6}$ cells per kg \\
Clinical administration frequency & Monthly; 6 doses \\
Animal pathogenic model & Yes \\
Genetic manipulation & No \\
\hline
\end{tabular}



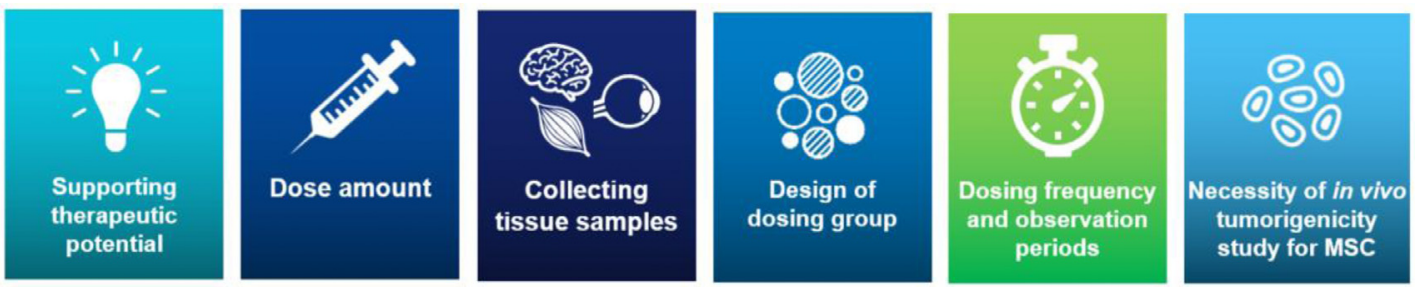

Figure 2. Main points where differences in perspective among the five Asian respondents were recorded.

lists all participating facilitators and panelists, and the facilitators picked up the discussion items based on the survey results of WG1.

\section{Pharmacology and CKBD}

As pharmacology and cellular kinetics are inseparable in understanding the pharmacological effects of cells in nonclinical studies, and to translate them into a clinical setting, they were combined in this panel discussion. Based on the survey results, five topics were raised for discussion, two of which pertained to pharmacology, and the rest CKBD based.

The first topic in pharmacology was the number of dose groups in an animal study. In the survey, the Japanese respondents set only one dose group, while the respondents from other countries and regions in WG1 set multiple. This difference seemed to reflect different aims of the in vivo pharmacology studies. For product proof-of-concept (PoC), a single-dose group study could be acceptable; however, an animal study with multiple dose groups could reveal further insights into the prediction and understanding of pharmacological action within a clinical setting. The facilitator asked regulators of Japan, Korea and India for their perspectives:

\section{Japanese regulator}

We agree that one of the most important aims of in vivo studies in Japan is to demonstrate the PoC of the product; therefore, studies with only one cell dose group are acceptable.

\section{Korean regulator}

The first purpose of a nonclinical pharmacology study is to show the PoC of efficacy on the intended disease for clinical trials. Therefore, it is not mandatory to conduct a multidose group study; however, the use of multiple dose groups might be ideal, as dose-response impact might provide clear evidence of efficacy itself and could help explore the optimal dose range for clinical trials. Nevertheless, a single dose group will show satisfactory efficacy, especially when a reliable animal model and control groups are established. In the case of the virtual product of mesenchymal stromal cells (MSCs), it is possible to use one dose group.

Table 4

Facilitators and panelists participating in the panel discussion of WG1.

\begin{tabular}{ll}
\hline Facilitators, WG1 members & Panelists, Regulatory agencies \\
\hline Pharmacology and CKBD & V.G. Somani (India) \\
Hiroshi Karasawa (Japan) & Sanjeev Kumar (India) \\
Yuu Moriya (Japan) & Kellethur Srinivasan (Singapore) \\
Pawan Kumar Gupta (India) & Seeun Kim (Korea) \\
Tomohiro Yoneda (Japan) & Wei-Chun Kan (Taiwan) \\
General toxicology & Kun-Chin Ho (Taiwan)Fong-Chun \\
Yukari Fujiwara (Japan) & Huang (Taiwan) \\
Bryan Choi (Korea) & Misaki Naota (Japan) \\
Dong-sik Ham (Korea) & \\
Tumorigenicity & \\
Kiyoko Bando (Japan) & \\
Takeshi Watanabe (Japan) & \\
\hline
\end{tabular}

\section{Indian regulator}

The use of multiple dose groups is a requirement of the New Drugs and Clinical Trials rules in India. The assessment of PoC in an appropriate animal disease model is based on the ultimate clinical indication. According to the Indian perspective, the PoC is needed to optimize the route of administration (ROA) and highlight potential mechanisms of action (MOAs). This study should yield dose levels for optimum therapeutic efficacy. The selection of an animal model for the duration of the study should adequately justify the persistence and functionality of the administered cell products. India prefers to have three dose groups and one control. The highest dose should produce observable toxicity, whereas the lowest dose should not, and the middle dose should be comparable to the intended therapeutic dose (TD).

The second topic in pharmacology was on estimating the clinical cell dose from the animal cell dose. In the survey, all members in WG1 recognized the difficulty in this task, and many preferred to refer to the clinical dose used in previous clinical trials of similar products. Simultaneously, some countries and regions in WG1 believed that thorough pharmacokinetic (PK)/pharmacodynamic (PD) assessment is necessary for this conversion. The facilitator asked regulators how to best support and estimate the clinical cell dose based on nonclinical pharmacology data:

\section{Japanese regulator}

For conventional pharmaceuticals, dose response is generally confirmed in a nonclinical study; however, in the case of CTPs, it is difficult to conduct quantitative assessments. Therefore, it is not necessary to determine the clinical dose based on the results of the animal studies. If the clinical data of a similar product are available, it would be appropriate to base decisions on such data.

\section{Taiwanese regulator}

I agree to utilize the available human experience of similar products to estimate the clinical dose of the investigational cell products. When no experience with similar products is available, explanations based on factors such as body weight or the cavity volume of the knee joint for the virtual case might be useful to estimate the clinical dose. This should be justified by sponsors. To initiate clinical studies, not only pharmacological data but also safety data should be considered for clinical dose estimation.

\section{Korean regulator}

I agree that it is difficult, and sometimes unmeaningful, for CTPs to estimate the optimal dose from animal studies' results. Indeed, using clinical doses from historical experience might be an alternative approach. If the product is systemically administrated, it is recommended to use the conversion factor based on kilogram body weight (not considering the usual surface area). However, in the case of a local intra-articular (IA) administration, such as with a virtual MSC model, it might be reasonable to use a conversion factor based on the volume of the joint cavity between the animal and human. I agree with the Taiwanese regulator in that the clinical doses proposed for human study were not just derived from one pharmacology study, but from pharmacology, toxicology and CKBD studies together. 
The first CKBD topic discussed was the purpose of a nonclinical CKBD study. In the WG1 survey, some correlated study settings were based on toxicology, while others were based on pharmacology. In this session, feedback from the regulatory agencies was obtained on the most important factors to consider in nonclinical CKBD study settings:

\section{Japanese regulator}

Several guidelines for CTPs in Japan have described the CKBD objectives as estimating the survival of cells or tissues and the duration of the effects when administered to patients. Another objective is to determine whether the intended efficacy can be successfully achieved. In addition, it is believed that the cellular kinetics and distribution obtained from the CKBD study can provide useful information for clinical regimens.

\section{Korean regulator}

The main purpose of the BD study of CTPS is to estimate cellular kinetics in the clinical microenvironment, because this information is not obtained from clinical sampling. BD study results provide important information for clinical design and safety monitoring. The important factor in setting the BD study is reflecting the clinical condition while considering the characteristics of MSC products, such as homing effect, possibility of engraftment, or differentiation in some environments. Therefore, some important factors are a suitable disease model, clinical equivalent administration routes, and detection methods for MSC products.

\section{Indian regulator}

Nonclinical CKBD studies have been conducted to support the use of therapeutics in humans. These studies were conducted as a part of nonclinical pharmacology and toxicology studies. According to our rules, toxicokinetic studies were conducted to assess the systemic exposure achieved in animals and their relationship to dose levels and the time course of toxicity studies. Another objective of the CKBD study is to relate the exposure achieved in toxicity studies to toxicological findings and contribute to the assessment of the relevance of these findings to clinical safety. Providing information in conjunction with toxicity findings contributes to the design of subsequent nonclinical toxicity studies.

\section{Taiwanese regulator}

Taiwan holds similar opinions to those of the other panelists. Tissue distribution, persistence, trafficking and other properties are usually described by CKBD studies; therefore, these characteristics should be investigated in the analyses.

\section{Singaporean regulator}

Singapore would be requesting an immunodeficient animal model. Regarding nonclinical CKBD studies, it is closely related to pharmacology and toxicology studies; therefore, in the case of the virtual product, the most essential factor to consider in the nonclinical CKBD study for MSCbased CTPs to treat rheumatoid arthritis (RA) would be cytokine biodistribution and concentration. Because RA indication mandates mostly local IA injection in a clinical setting, the chances for MSCs to circulate to other tissues are likely relatively low, in which case MSC detection may be less clinically relevant. Collecting tissue samples in addition to the injection site may not be necessary.

The second topic on CKBD was about the remarkable differences in tissue selection among the regulatory guidelines. The tissues to be examined in CKBD studies are defined in the regulatory guidelines of China and Korea, with the Korean regulator providing the rationale behind tissue selection:

\section{Korean regulator}

As mentioned previously, the BD study condition should ideally be close to the clinically expected environment, when considering the product's characteristics. Therefore, the disease animal model and clinical administration routes are suggested in Korea's guidelines, and a maximum feasible dose (MFD), or more than the anticipated clinical equivalent dose, is reasonable for obtaining the overall distribution profile. In contrast, dosing times, frequency, and observation time points can be modified depending on the clinical schedule, as well as the distribution and elimination profile of the product. Regarding sampling tissue, systemic administration generally requires collecting major organs and tissues, including the reproductive ovary and testis; however, in the case of local IA administration, such as with the virtual MSC model, limited exposure is expected, and reduced tissue sampling, including the injection site over the target area, can be justified.

The third topic was the selection and validation of cell detection methods for CKBD, for which no clear validation criteria can be found within the regulatory guidelines. In this situation, pharmaceutical industries wondered about the appropriate method to detect the cells and how the validation item criteria should be established. Regulatory perspectives were shared between Japan, Singapore and Korea:

\section{Japanese regulator}

Japan does not have any specific recommendations on the cell detection method for regulatory use. It should be chosen on a case-by-case basis, and sponsors should clarify the scientific rationale of the method selected. Validation is also necessary for the test results to be of value.

\section{Singaporean regulator}

Singapore agrees with the PMDA's comment that it is best determined on a case-by-case approach, as several methods should be relevant to the product, and the method should be validated.

\section{Korean regulator}

Korea has a guideline on BD study and validation, generally recommending quantitative polymerase chain reaction ( $q P C R$ ) for its high levels of sensitivity; however, sometimes the MOA of MSC products is based on cell engraftment and differentiation of the target tissue. In such cases, immunohistostaining and imaging techniques can be helpful for detecting specific surface markers of differentiated cells. Validation generally requires typical analytical methods: accuracy, linearity, detection range and detection limit.

Clear explanations by the regulators can help to understand the different requirements among the countries and regions and to prepare the optimal nonclinical package of CTPs. Simultaneously, a flexible attitude of regulatory agencies toward the emerging and evolving field of cell therapy can be beneficial.

\section{General toxicology}

The objective of this session was to capture the five participatory countries and regions' essential views on a case-by-case safety assessment of the MSC-based CTPs. The survey results in WG1 showed clear differences among the countries and regions regarding their approach to general toxicology assessments for model therapy. Discussions were held with the regulatory agencies regarding the number of dose groups, dose frequency, observation period, animal models, ROA, and immunogenicity assessment in the session.

Number of dose group. According to the WG1 survey, Japan set two times of repeated dosing within a single dose group to identify product hazards, whereas all other countries and regions in WG1 set a repeated dose study across multiple dose groups to determine the dose dependency of toxicity. A Japanese regulator commented on the rationale of why one dose group would be considered sufficient:

\section{Japanese regulator}

The objective of toxicology studies in animal models is to evaluate the potential risks to humans. There are two types of toxicities: one is the ontarget toxicity caused by the therapeutic cells themselves, and the other is off-target toxicity caused by non-cell components, such as the cell 
stock solution and impurities. In terms of on-target toxicity, nonclinical studies are not a suitable model for quantitative safety assessment, whereas for off-target toxicity, there are no specific safety concerns of interest regarding the non-cellular components of the virtual CTPS. Therefore, identifying the maximum tolerated dose (MTD) in toxicity studies is nonessential.

Dose frequency. In WG1, all countries and regions, except for Japan, set the dose frequency regimen following the planned clinical protocol (once a month, six times of repeated doses); however, Japan in WG1 considered two administrations of a single dose as sufficient. China and India in WG1 requested separate studies of single and multiple administrations, and India in WG1 also requested 14 daily repeated administrations. Regulators from India, Japan and Korea offered the following rationales for their schemes:

\section{Indian regulator}

For single-dose toxicity studies in animals, a dose of $2 \mathrm{~g}$ per $\mathrm{kg}$ of body weight or 10 times the normal dose intended for humans is used, whichever is higher. Animals were observed for 14 days after drug administration to establish the minimal lethal dose (MLD) and MTD. If possible, the target organs of the toxicity study should also be determined. Mortality should be observed for up to 7 days after parenteral administration. Single-dose toxicity studies should be conducted in two rodent species, namely mice and rats. Where rodents are known to be poor predictors of human studies, they should be established in nonrodent species. As for repeated dose toxicity studies, these are to be conducted in a minimum of two mammalian species, of which one should be nonrodent. There are separate rules for single- and repeated-dose toxicity studies. If the results of the single-dose toxicity studies are acceptable, then repeated-dose studies may not be required. In various instances where the drug or the product has a long half-life, incomplete elimination or an unanticipated organ toxicity, repeated-dose toxicity studies are preferred. In the virtual product case where cells will be given monthly for 6 months, repeated-dose toxicity is required. Currently, there are no specific guidelines for these product types, and presently, the New Drugs and Clinical Trials rules are followed. Over time, new guidelines for such products will be formulated.

\section{Japanese regulator}

The duration of administration and the need for repeated dosing in toxicity studies should be based on the clinical trial design. Considering the accumulation and survival of administered cells in vivo, if cell accumulation is not expected, a single-dose toxicity study is considered sufficient to assess the potential risks of repeated-dose clinical trials. Alternatively, if cell accumulation is expected when administrated repeatedly to humans, the risks should generally be addressed by a repeated-dose toxicity study.

\section{Korean regulator}

Generally, the study setting of a repeated-dose toxicity study should reflect the clinical protocol. The dose frequency, dose interval, or monitoring periods can be flexibly modified in consideration of the animal model, ROA, or the results of the BD study. For example, when the virtual MSC model uses local administration and is expected to show a limited distribution in the IA joint cavity and have a rapid elimination tendency, three to six repeated dosing schedules across a 14-week monitoring period may be reasonable.

Observation period. The WG1 survey also revealed notable differences among the countries and regions regarding the period of observation. Japanese and Taiwanese regulators justified their rationale for accepting relatively short observation periods ( 2 to 6 weeks). India in WG1 explained both a short observation period of 2 weeks and a longer period of 13 weeks, and the Indian regulator made his remark on their regime. China in WG1 similarly sets both short and long observation periods in separate studies, whereas Korean and Singaporean regulators remarked on their longer, 13-week observation periods implemented.

\section{Japanese regulator}

An observation period of 2 weeks is considered acceptable for the acute toxicity study of the model product. In this case, 13 weeks of chronic toxicity is not requested.

\section{Taiwanese regulator}

The sponsors are encouraged to conduct a pilot study to determine the observation period.

\section{Indian regulator}

The observation period can vary from $14,28,90$ or 180 days for toxicity studies depending on the clinical indication and duration.

\section{Korean regulator}

A sufficient observation period is needed to observe for delayed toxicity of the MSC product. The long observation period can be readily justified, particularly when the product has shown a persistent distribution in the target tissue.

\section{Singaporean regulator}

In general, the standard observation period for the repeat-dose toxicity is 13 weeks, with six administrations among the three groups; however, when considering the indication and distribution of MSCs, justification for other time periods can be explored.

Animal model for general toxicity. According to the WG1 survey, Korea and Japan employ a single species of immunodeficient mice or rats for the general toxicity study. Alternatively, India, China and Taiwan in WG1 responded that normal, non-immunosuppressed animals could be used. Regulators' rationale from Japan, Taiwan and India were obtained for this topic, where both Taiwanese and Indian regulators unexpectedly claimed a preference for immunodeficient or immune-compromised animals during general toxicity assessments.

\section{Japanese regulator}

One species is sufficient for the general toxicity study because, unlike chemical entities, metabolic differences between species are not expected in CTPs. Additionally, in a nonclinical study of CTPs, xenogeneic immune reactions to human cells can occur; therefore, testing on a single species of immunodeficient animals is sufficient.

\section{Taiwan regulator}

Immunodeficient or immune-compromised animal models using mice or rats, should be considered.

\section{India regulatory \\ Immunodeficient animals are sometimes considered depending on the case.}

ROA for toxicity studies. In WG1, Japan, Korea and Taiwan selected only IA routes of administration, following clinical protocol; however, India and China required systemic routes of intramuscular (IM) or intravenous (IV) administration, in addition to IA. In particular, India employed single administrations via IA, IV and IM in general toxicity studies, with 2- and 13-week observation periods, and adopted the 14-administration studies over 2 weeks through IV injection alone, followed by a 2 -week observation period. The Indian regulator supported the survey results, agreeing that a systemic toxicity study is necessary to address the potential adverse effects of CTPs on patients' bodies. 
Immunogenicity assessment. The regulations of Japan and the other countries differed somewhat in their assessment of immunogenicity. All representative countries and regions except Japan required immunogenicity test results, whereas Japan considered such assessments as non-essential for MSCs, as it is difficult to infer immunogenicity in humans through animal model data, and allogeneic MSCs are commonly reported to be less immunogenic in humans. The Korean regulator supported the survey results, clarifying that immunogenicity concerns should be addressed for allogeneic MSC-based CTPs. Characterization of immunogenic properties of MSCs by human leukocyte antigen (HLA) typing and allogeneic mixed lymphocyte reaction (MLR) is generally recommended for in vitro studies. Comments from Singaporean and Indian regulators expressing less stringent views were also received:

\section{Singaporean regulator}

We agree with the PMDA's assessment that it is difficult to evaluate human immunogenicity via animal models. We have thus not required an immunogenicity assessment.

\section{Indian regulator}

There are not currently any specific requirements as part of current regulations. If it is feasible for the sponsor, then this immunogenicity assessment can be conducted as a part of a repeated-dose toxicity study; however, it is neither a compulsory nor regulatory requirement as of now.

Regulatory agencies were found to maintain different views on the approaches and concepts regarding general toxicity studies of the virtual MSC-based product; however, some flexibility and logical approaches available for developers to adjust study schemes were also identified.

\section{Tumorigenicity}

According to the WG1 survey, all countries and regions held the same belief that MSC-based CTPs are less tumorigenic than embryonic stem (ES) and induced pluripotent stem (iPS) cell-derived CTPs; however, differences between countries and regions were identified in the two regulatory requirements: The first deals with whether in vivo tumorigenicity studies are mandatory for MSC-based CTPs. In countries other than Japan in WG1, such studies were common for MSC-based CTPs; in particular, India and China have domestic guidelines for in vivo tumorigenicity studies. In contrast, these studies are not required in Japan for MSC-based CTPs produced under the Good Gene, Cellular, and Tissue-based Products Manufacturing Practice (GCTP), nor is it required for some cases in Korea. Accordingly, comments were sought from Indian and Japanese regulators as conservative and flexible representatives, respectively:

\section{Indian regulator}

It may not be mandatory to conduct a tumorigenicity study in every case. It depends on its use for longer clinical durations and in chronic illnesses.

\section{Japanese regulator}

In principle, concerns over tumorigenicity of CTPs vary depending on the differentiation stage of the cells, manufacturing process, culture period, and experience of clinical use for similar products. For MSCs, in vivo studies are generally not required, as they maintain a lower risk of tumorigenicity compared to ES with iPS cells. In vitro studies are sufficient to evaluate tumorigenicity.

Common considerations, however, were found amid both camps; namely, that whether or not to conduct in vivo tumorigenicity studies should be based on the material, manufacturing process, and clinical usage.

The second difference is associated with the observation period of tumorigenicity studies. Survey results indicated that a 6-month duration was set for MSC-based CTPs in China, India, Korea and Taiwan.
Comments from the latter three regulators were recorded about the rationale of the observation period. Additionally, each regulator was asked whether this duration applied broadly to any kind of CTPs, regardless of product profile or characteristics, such as cell persistence or potential tumorigenicity risk of the product. In vivo tumorigenicity studies for MSC-based CTPs are not mandatory in Japan, but Japanese regulators still provided opinions on the observation period duration of in vivo tumorigenicity studies when needed. Additional comments were also received from Singaporean regulators:

\section{Indian regulator}

Six months is a generic or generalized requirement; however, it is dependent on the clinical duration and nature of the product.

\section{Taiwanese regulator}

For different CTP types, a sponsor should provide rationale for the selected study design; thus, they are encouraged to consult with a regulatory agency.

\section{Korean regulator}

The observation period of in vivo tumorigenicity study is dependent on the product characteristics, such as cell origin, age, treatment level and karyotyping, as well as residual and differentiated stem cell fraction. For typical MSC-based CTPs, 6-month observation is considered suffcient; however, pluripotent stem cell-derived MSCs are considered to have high tumorigenic potential, and observations $>12$ months are required in such cases.

\section{Japanese regulator}

If in vivo studies were to be conducted, the observation period would be determined on a case-by-case basis, depending on the level of risk concern.

\section{Singaporean regulator}

It depends on the extent of the manipulation that MSCs have undergone, and whether other studies have been done, such as karyotyping. Greater levels of manipulation raise issues with genomic instability, which in turn is dependent on the product characteristics and source. This virtual product was not iPSC-based, but if it had been, additional considerations would be needed for adequate characterization.

Accordingly, it was understood that case-by-case considerations are needed for setting the observation period of tumorigenicity studies. On the industry side, the duration of the tumorigenicity study has a significant impact on product development timelines, and it is hoped that the findings here will provide a good starting point for future discussions and the potential harmonization of tumorigenicity evaluation across the continent.

Key differences and considerations among the regulatory agencies with respect to discussion outlined in WORKING GROUP 1 session are summarized in Table 5.

\section{Working Group 2: Quality Panel Discussion}

\section{Introduction to panel discussion}

\section{Regulations in Asia, the United States and Europe on starting cells for} CTPs and risk-based approaches

WG2 reviewed guidelines for eligibility on starting cells in India, China, Korea, Taiwan and Japan, in addition to benchmarks from the US and EU, for comparing requirements on donor screening tests and interviews, informed consent, collection sites, window periods, traceability and legitimacy. All countries and regions require donor screening tests for human immunodeficiency virus (HIV), hepatitis B virus (HBV) and hepatitis C virus (HCV). Tests for other viruses, such as human T-cell leukemia virus (HTLV), Epstein-Barr virus (EBV), human parvovirus B19 (PVB19) and West Nile virus (WNV), and bacteria such as Treponema pallidum (syphilis), Chlamydia trachomatis 
Table 5

High-level summary of key differences and considerations among the regulatory agencies in WORKING GROUP 1 session.

\begin{tabular}{|c|c|c|c|}
\hline \multicolumn{2}{|l|}{ Topics } & \multicolumn{2}{|c|}{ Key points from each regulatory agency } \\
\hline \multirow[t]{6}{*}{ Pharmacology } & \multirow[t]{3}{*}{ The number of dose groups in an animal study } & Japan & Studies with only one cell dose group are acceptable. \\
\hline & & Korea & The use of dose groups more than one might be ideal, but not mandatory. \\
\hline & & India & It is preferable to have three dose groups and one control. \\
\hline & \multirow[t]{3}{*}{ The estimation of the clinical cell dose from animal cell dose } & Japan & $\begin{array}{l}\text { It is not necessary to determine the clinical dose based on the results of the } \\
\text { animal studies. }\end{array}$ \\
\hline & & Taiwan & $\begin{array}{l}\text { Explanations based on factors such as body weight or the cavity volume of the } \\
\text { knee joint for the virtual case might be useful. }\end{array}$ \\
\hline & & Korea & $\begin{array}{l}\text { It might be reasonable to use a conversion factor based on the volume of the } \\
\text { joint cavity between the animal and human. }\end{array}$ \\
\hline \multirow[t]{5}{*}{ CKBD } & \multirow[t]{3}{*}{ The purpose of a nonclinical CKBD study } & Japan & $\begin{array}{l}\text { The objectives are to estimate the survival of cells or tissues and the duration } \\
\text { of the effects when administered to patients, and to determine whether the } \\
\text { intended efficacy can be successfully achieved. }\end{array}$ \\
\hline & & Korea & $\begin{array}{l}\text { The main purpose is to estimate cellular kinetics in the clinical } \\
\text { microenvironment. }\end{array}$ \\
\hline & & India & $\begin{array}{l}\text { The objective is to support the use of therapeutics in humans. The purposes of } \\
\text { toxicokinetic studies are to assess the systemic exposure achieved in ani- } \\
\text { mals and their relationship to dose levels and the time course of toxicity } \\
\text { studies, and to relate with toxicological findings. }\end{array}$ \\
\hline & \multirow[t]{2}{*}{ The selection of cell detection methods } & Japan & $\begin{array}{l}\text { There are no specific recommendations on the cell detection method for regu- } \\
\text { latory use. }\end{array}$ \\
\hline & & Korea & $\begin{array}{l}\text { qPCR is generally recommended for its high levels of sensitivity. Immunohis- } \\
\text { tostaining and imaging techniques can be helpful for detecting specific sur- } \\
\text { face markers of differentiated cells. }\end{array}$ \\
\hline \multirow[t]{8}{*}{ General toxicology } & \multirow[t]{3}{*}{ Dose frequency } & India & $\begin{array}{l}\text { Single-dose toxicity studies should be conducted in two rodent species. } \\
\text { Repeated dose studies are also required. }\end{array}$ \\
\hline & & Japan & $\begin{array}{l}\text { If cell accumulation is not expected, a single-dose toxicity study is considered } \\
\text { sufficient to assess the potential risks of repeated dose clinical trials. }\end{array}$ \\
\hline & & Korea & $\begin{array}{l}\text { When a limited distribution in the IA joint cavity and a rapid elimination are } \\
\text { expected, } 3 \text { to } 6 \text { repeated dosing schedules across a 14-week monitoring } \\
\text { period may be reasonable. }\end{array}$ \\
\hline & \multirow[t]{5}{*}{ Observation period } & Japan & $\begin{array}{l}\text { An observation period of } 2 \text { weeks is considered acceptable for the acute toxic- } \\
\text { ity study of the virtual product. }\end{array}$ \\
\hline & & Taiwan & $\begin{array}{l}\text { The sponsors are encouraged to conduct a pilot study to determine the obser- } \\
\text { vation period. }\end{array}$ \\
\hline & & India & $\begin{array}{l}\text { The observation period can vary: } 14 \text { days (acute toxicity) and } 28,90 \text { or } \\
180 \text { days (sub-chronic toxicity) for toxicity studies depending on the clinical } \\
\text { indication and duration. }\end{array}$ \\
\hline & & Korea & $\begin{array}{l}\text { A sufficient observation period is needed to observe for delayed toxicity of the } \\
\text { MSC product. }\end{array}$ \\
\hline & & Singapore & $\begin{array}{l}\text { In general, the standard observation period for repeat-dose toxicity is } 13 \\
\text { weeks with } 6 \text { administrations. However, when considering the indication } \\
\text { and distribution of MSCs, justification for other time periods can be } \\
\text { explored. }\end{array}$ \\
\hline \multirow[t]{2}{*}{ Tumorigenicity } & \multirow[t]{2}{*}{ In vivo assessment } & India & $\begin{array}{l}\text { It may not be mandatory to conduct a tumorigenicity study in every case. It } \\
\text { depends on its use for longer clinical durations and in chronic illnesses. }\end{array}$ \\
\hline & & Japan & $\begin{array}{l}\text { For MSCs, in vivo studies are generally not required. In vitro studies are suffi- } \\
\text { cient to evaluate tumorigenicity. }\end{array}$ \\
\hline
\end{tabular}

and Neisseria gonorrhoeae were dependent on the countries and regions and type of cells or tissues collected. In Japan, Taiwan, the US and the EU, a donor screening test for transmissible spongiform encephalopathy (TSE)/Creutzfeldt-Jakob disease (CJD) is also required. A second donor screening test with a window period consideration is unconditionally required in Japan. WG2 concluded that each country or region maintained its own specific requirements for the quality of starting cells based on the history of health care, the remedy system and the situation of infectious disorders. Although gaps exist among countries and regions, a risk-based approach was proposed to help reconcile these disparities via regulations, thus facilitating the development of CTPs across the globe. Three specific areas were addressed in this consideration: (1) donor location, (2) window period of the PCR and serologic tests and (3) additional viral tests on cell banks or final products.

\section{Comparability of MSC-based products}

Comparability is used to demonstrate product equivalence after a process change, including media component adjustments, donor/starting material changes, and changes of processing technologies; however, it is extremely challenging to develop or standardize a common characterization test for cell-based products owing to the biological variance among cells and the lack of established standardized references.

In the WG2 survey, comparability assessments of MSCs were considered within the scope of routinely used physicochemical, biological and functional characterization tests, particularly for immunosuppressive capabilities. The corresponding advantages and disadvantages of these tests are listed and summarized in Tanaka et al. [2]. The discussion here focused on cost- and time-effectiveness, accessibility, reproducibility and suitability of the tests for comparability studies. The recommendations of each test were based on the discussions and opinions collected from WG2 members.

To date, there are $>1,000$ ongoing clinical trials of MSC-based products globally, so it would be very beneficial for developers and facilitate global development if characterization testing items and methods can be harmonized or standardized.

\section{Panel discussion with regulatory agencies (India, Singapore, Korea,} Taiwan and Japan)

After a presentation from the industry, WG2 proceeded with a discussion featuring invited panelists from the aforementioned 
Table 6

Facilitators and panelists of WG2 discussions.

\begin{tabular}{ll}
\hline Facilitators (WG2 members) & Panelists (regulatory agencies) \\
\hline Ryan Chang (Taiwan) & V.G. Somani (India) \\
Shinobu Kuwae (Japan) & Sanjeev Kumar (India) \\
& Kellethur Srinivasan (Singapore) \\
& Seeun Kim (Korea) \\
& Wei-Chun Kan (Taiwan) \\
& Fong-Chun Huang (Taiwan) \\
& Atsushi Nishikawa (Japan) \\
& Yoji Sato (Japan)* \\
\hline
\end{tabular}

* Expert from academia.

regulatory agencies (Table 6). Four topics were on the agenda: (1) starting cell eligibility, (2) risk-based approaches, (3) comparability studies and (4) stability data for shelf-life extension.

\section{Starting cell eligibility}

All eligibility guidelines for MSCs from the surveyed countries and regions indicated the presence of a common framework requiring appropriate assurances of the starting material cells; however, variations in test items and potential risk assessments were present based on respective health care history and governance, as well as the prevalence of various infectious disorders and their remedies. This informed the first question for the panel: What are the primary features of regulations determining the eligibility of starting cells for MSC products in your country and region?

From the panel, HIV, HBV and HCV tests are commonly required for donor tissue cells. Testing of HTLV (type I and type II) and cytomegalovirus (CMV) is also mandatory for eligibility with leukocyterich cells, as was noted by panel regulators from Taiwan and Korea. Additionally, in Japan, it is necessary to screen for EBV, PVB19 and WNV. Treponema screenings are required for donor suitability in all participating countries, whereas other infectious elements (e.g., Chlamydia, Neisseria and TSE) require screening confirmation in Korea, Taiwan and Japan.

There are two primary considerations for viral testing within these regulations: one is driven by the prevalence of infectious diseases within the country, and the other is based on the potential severity of viral infections and possible complications in patients. These were further illustrated in comments made by the regulators of Korea and Japan:

\section{Korean regulator}

In Korea, donor screening tests are established considering the potential risk of each infectious microbe, in addition to domestic prevalence. EBV and PVB19 are known to have a low prevalence in Korea; therefore, they are not listed.

\section{Japanese regulator}

The required levels of testing for each virus are mainly determined by the severity of the disease caused by the virus. It is important to ensure that donors are not infected with human viruses, which may cause serious diseases such as immunodeficiency, hepatitis and leukemia.

Risk-based approach: Donor location, window period, and additional virus tests

The second panel discussion topic aimed to reconcile gaps between the respective regulatory guidelines and the proposed riskbased, case-by-case approach, possibly providing a certain level of flexibility when considering perceived actual risks. Accordingly, the second question to the panel inquired about regulators points of view regarding risk assessment based on a case-by-case assessment of products. The discussions focused on three areas within these respective guidelines: (1) donor location, (2) window period of PCR and serological tests and (3) additional virus testing on the master cell bank (MCB).

Donor selection criteria, conducted through personal interviews and informed consent, include individual donors' genetic profiles, travel histories, and other additional questions such as personal and family medical histories to establish donor qualifications. Further, a consensus was reached regarding the importance of location where donor tissues and cells are to be collected, as depicted by the comments from the Indian regulator:

\section{Indian regulator}

Donor location is an important criterion for assessing the risk of a final product. Additional checks or controls may also be required. The sponsor of the product must justify the donor location, as the product should be tested based on this information. This is true particularly with respect to the prevalent communicable diseases within the given country and region, with higher potential levels of transmission due to the use of donor tissues, such as cord blood, placenta or umbilical cord.

Whereas donor locations, collection sites, and necessary confirmatory credentials are universal requirements, differences exist within the regulating window period re-tests, save for China and Korea, where no such tests are required. The corresponding rationale stems from two different risk perspectives: The first involves the perceived adequacy by India, Korea, and Taiwan at controlling the infectious viral factors of starting stage, and final product materials, whereas the second involves examining end-to-end and in-process assurances over the course of cell manufacturing. The Korean regulator provided similar views to those of the Taiwanese regulator and considered its 7-day re-testing an integral component of donor screening at the beginning stages. Comparatively, the Japanese regulator elaborated on the window-period considerations and, accordingly, additional viral testing at the cell bank level. This issue was highlighted by the broader comments of Dr. Yoji Sato (below), who participated in the panel as an academic expert. Despite the above differences in regulating donor eligibility, all panel participants expressed flexibility in assessments on a case-by-case basis:

\section{Korean regulator}

$A$ request was made for both serological antigen and nucleic acid tests (NATs) for HBV, HCV and HIV to be performed as a second donor screening test.

\section{Japanese regulator}

For HIV, HBV, HCV and HTLV, second donor screening tests should be performed regardless of whether they are tested by serological tests or NATs. Notably, the results did not change even when both test types were performed, as the possibility of false negatives cannot be ruled out when samples are below both tests' detection limits.

If secondary donor screening tests have not been performed, additional virus tests on the MCB or final product are considered useful. For example, if the MCB has already been established, and no plans exist for creating new MCBs, a certain level of risk management has been attained by additional virus tests on that cell bank.

\section{Dr. Sato}

In the EU and the US, even if the raw material donors are tested for viruses only once before or after cell collection, it is sufficient if the viral safety is evaluated based on a window period at a later stage (up to the final product); however, in Japan, it is necessary to demonstrate viral safety considering the window period at the raw material stage. In other words, it is necessary to conduct a virus test twice for donors at the raw material stage, creating a potential obstacle for introducing products developed overseas into Japan. 
Taiwanese regulator

A case-by-case consideration of donor eligibility is used. Taiwan requires donor testing for $\mathrm{HIV}, \mathrm{HBV}$ and $\mathrm{HCV}$, and there are no problems for cell products with tissue donors from other countries. In addition, HTLV1/2 and CMV are required in most countries. Therefore, if a sample has been collected from another country where it was accepted for clinical trials, there is no problem for the cells to be accepted for IND application in Taiwan. If the donor screening test is incomplete, then conducting additional virus tests on the cell bank may be considered.

All panel members indicated a certain level of regulatory adaptability, but the responsibility was borne by the sponsors and investigators to present clear justifications for consideration. To gain additional clarity prior to submission, regulators further encouraged early engagements and communications by the sponsors.

\section{Comparability study}

WG2 inquired about the possibility of harmonizing testing items and methods for comparability assessments of undifferentiated MSCbased products, subject to changes in the manufacturing processes. All panelists shared a common belief that harmonization of the comparability study is quite challenging and should be assessed case-bycase, even when the case is limited to undifferentiated MSC-based products. Panelist comments were as follows:

\section{Taiwanese regulator}

In essence, the comparability study is assessed case-by-case, dependent on what kind of change is being addressed or the influence of this change on cell quality attributes. Basically, comparability should include the growth rate, differentiation ability, cell surface markers, etc. If the cell product is going through late-phase clinical trials, especially in late phase 2 or phase 3 trials, the sponsor should conduct the clinical trial and MOA relevance, where the potency assay should be applied for comparability studies to ensure that the changes do not affect cell functionality.

\section{Singaporean regulator}

Indeed, it is quite challenging when it comes to comparability, and it may not be possible to harmonize the functional characterization tests, as they are related to the functional and biological characterizations of the final product. As long as the test method is relevant to the intended purpose and validated, it can still be acceptable.

\section{Indian regulator}

The sponsor has to justify and provide the necessary documents, along with validated methods; thus, it works on a case-by-case basis. Normally, an automated cell counter is used to check cell viability. In addition, a flow cytometry-based assay is also conducted, and the population doubling time is calculated to inspect the replicative capability. It is the responsibility of the sponsor to justify how the method used is validated, and how it most useful for assessing the intended characterization.

\section{Korean regulator}

These characteristics belong to the areas of product-specific characteristics, scientific knowledge, and technological advancements. If the characteristics are critical quality attributes, then test items, analytical methods and acceptance criteria should be provided by companies and researchers, which can be diverse, depending on the product and the company's approach and strategy; thus, it is not within the area of regulatory authorities to harmonize them.

\section{Japanese regulator}

It will be handled on a case-by-case basis. Evaluation items may be adjusted depending on changes in the manufacturing processes or product development concepts, such as target diseases. Therefore, if one tries to address all cases, they may end up with guidance that provides an overview, such as the International Council for Harmonization of Technical Requirements for Pharmaceuticals for Human Use (ICH) Q5C guidelines. In addition, to encourage the development of diverse products, it may be disadvantageous to strictly harmonize and define characterization items.

\section{Stability data for shelf-life extension}

The European Medicines Agency (EMA) draft guideline on quality, nonclinical and clinical requirements for investigational advanced therapy medicinal products (ATMPs) in clinical trials describes stability as follows: "The foreseen storage period should be based on longterm, real-time and real-temperature stability studies, as described in ICH Q5C. Extension of the shelf life beyond the period covered by real-time stability data may be acceptable if supported by relevant data, including accelerated stability studies and/or relevant stability data generated with representative material. The maximum shelf life after the extension should not be more than double, or 12 months longer, whichever is the longest, than the period covered by realtime stability data obtained with representative batches."

The final topic of WG2 was to assess the possibility of extending CTPs' shelf life beyond the period covered by real-time stability at the clinical stage. Comments from Singaporean and Indian regulators suggested that this is possible; however, regulators from other countries and regions spoke on the difficulty in applying this concept to CTPs:

\section{Singaporean regulator}

It is quite difficult to employ ICH Q5C for CTPS, but the possibility of extending their shelf life beyond the period covered by the real-time stability in the clinical stage is dependent on the product storage conditions and accelerated study results. If cryopreserved, shelf life will be different from a fresh product that stored at ambient temperature. Therefore, several factors should be considered.

\section{Indian regulator}

ICH Q5C may not be truly applicable for such products. The extension of shelf life beyond real-time stability may be acceptable if it is supported by long-term stability storage data, including studies conducted under stress conditions. It must be justified with the statistical justification for analyzing the data generated for this extrapolation of the shelf life.

\section{Taiwanese regulator}

ICH Q5C may not be suitable for cellular therapy, as it is difficult to use some cell therapy stability data to predict the degradation rate of all cellular changes. Therefore, when assessing CTP stability, it cannot be extrapolated from the real-time stability to twice the shelf-life period. It is a very difficult challenge, particularly since relevant data and experience are lacking; thus, this concept cannot be used for CTPs.

\section{Korean regulator}

In Korea, there is a principle that the shelf life of investigational medicinal products, including all biological products, can be extended beyond the real-time stability data on the basis of accelerated stability data; however, there is no real case to apply this principle to CTPs, and no companies have submitted accelerated data to extend the shelf life. Gene therapy products, such as virus-like products, are often extended in shelf life according to this principle, but CTPs are not. Accordingly, neither accelerated nor stress data for CTPs can provide important information or meaningful differentiation of quality by stability.

\section{Japanese regulator}

Cell-based products are generally unstable; therefore, it is difficult to accurately estimate how long the shelf life can be extended. Currently, it is requested that the shelf life of investigational cell-based products should be set based on real-time stability data.

Key differences and considerations among the regulatory agencies with respect to discussion outlined in Working Group 2 session are summarized in Table 7. 
Table 7

High-level summary of key differences and considerations among the regulatory agencies in WORKING GROUP 2 session.

\begin{tabular}{|c|c|c|}
\hline \multirow{3}{*}{ Topics } & \multicolumn{2}{|c|}{ Key points from each regulatory agency } \\
\hline & Korea & EBV and PVB19 are known to have a low prevalence in Korea; therefore, they are not listed. \\
\hline & Japan & $\begin{array}{l}\text { It is important to ensure that donors are not infected with human viruses, which may cause serious diseases } \\
\text { such as immunodeficiency, hepatitis and leukemia. }\end{array}$ \\
\hline \multirow[t]{4}{*}{ Risk-based approaches and window period test } & India & $\begin{array}{l}\text { Higher potential levels of transmission due to the use of donor tissues, such as cord blood, placenta or umbilical } \\
\text { cord in prevalent counties or regions. }\end{array}$ \\
\hline & Korea & $\begin{array}{l}\text { A request was made for both serological antigen and NATs for HBV, HCV and HIV to be performed as a second } \\
\text { donor screening test. }\end{array}$ \\
\hline & Japan & $\begin{array}{l}\text { For HIV, HBV, HCV and HTLV, second donor screening tests should be performed regardless of whether they are } \\
\text { tested by serological tests or NATs. If the MCB has already been established, and no plans exist for creating } \\
\text { new MCBs, a certain level of risk management has been attained by additional virus tests on that cell bank. }\end{array}$ \\
\hline & Taiwan & $\begin{array}{l}\text { If the donor screening test is incomplete, then conducting additional virus tests on the cell bank may be } \\
\text { considered. }\end{array}$ \\
\hline \multirow[t]{5}{*}{ Comparability studies } & Taiwan & Basically, comparability should include the growth rate, differentiation ability, cell surface markers, etc. \\
\hline & Singapore & As long as the test method is relevant to the intended purpose and validated, it can still be acceptable. \\
\hline & India & $\begin{array}{l}\text { Normally, an automated cell counter is used to check cell viability. In addition, a flow cytometry-based assay is } \\
\text { conducted, and the population doubling time is calculated to inspect the replicative capability. }\end{array}$ \\
\hline & Korea & $\begin{array}{l}\text { These characteristics belong to the areas of product-specific characteristics, scientific knowledge, and techno- } \\
\text { logical advancements. }\end{array}$ \\
\hline & Japan & $\begin{array}{l}\text { Evaluation items may be adjusted depending on changes in the manufacturing processes or product develop- } \\
\text { ment concepts, such as target diseases. }\end{array}$ \\
\hline \multirow[t]{5}{*}{ Stability data for shelf-life extension } & Singapore & $\begin{array}{l}\text { The possibility of extending shelf life beyond the period covered by the real-time stability in the clinical stage is } \\
\text { dependent on the product storage conditions and accelerated study results. }\end{array}$ \\
\hline & India & $\begin{array}{l}\text { The extension of shelf life beyond real-time stability may be acceptable if it is supported by long-term stability } \\
\text { storage data, including studies conducted under stress conditions. }\end{array}$ \\
\hline & Taiwan & One cannot be extrapolate from the real-time stability to twice the shelf-life period. \\
\hline & Korea & $\begin{array}{l}\text { There is a principle that the shelf life of investigational medicinal products can be extended beyond the real- } \\
\text { time stability data on the basis of accelerated stability data; however, there is no real case to apply this princi- } \\
\text { ple to CTPs. }\end{array}$ \\
\hline & Japan & $\begin{array}{l}\text { Currently, it is requested that the shelf-life of investigational cell-based products should be set based on real- } \\
\text { time stability data. }\end{array}$ \\
\hline
\end{tabular}

\section{Conclusions}

A dialog between regulatory agencies and industries in the 4th APACRM is reported here. Through WG1 and WG2 panel discussions comprising major Asian regulatory agencies, regulation differences and their underlying rationales have been more clearly defined among the participating countries and regions. The virtual product setting, with a well-defined product profile, enabled the discussion of important issues on regulatory science regarding cell therapy, which can be expanded to inform discussions on other products as well. Knowledge sharing and collating data based on a discussion between industry and regulatory agencies is the first step toward harmonization of regulatory viewpoints surrounding cell therapy in Asian countries and regions. Further collaboration across other continents and countries, such as the US and EU, will assuredly help enhance the understanding of RM regulation beyond Asia.

The 5th APACRM in 2022 will further expand on the comparative surveys relating to the regulations of nonclinical (WG1) and quality (WG2) assessments. WG1 will introduce another type of RM modality (e.g., CAR-T therapy), and WG2 will explore the qualifications of CTP starting raw materials (e.g., ancillary materials).

It is hoped that an environment of harmonization is cultivated among the regulatory agencies from different countries and regions by sharing experiences regarding products under development and opinions on regulatory guidelines. Moreover, more proactive efforts on regulatory innovation (e.g., the necessity of new guidelines) regarding RM products can assist with regulatory harmonization and optimization across Asia, enabling the rapid delivery of CTPs to more patients, thus achieving market maximization of CTPs throughout Asia.

\section{Financial and competing interest disclosure}

This meeting was funded by the Forum for Innovative Regenerative Medicine (FIRM). The authors have no other relevant affiliations or financial involvement with any organization or entity involved with the subject matter or materials discussed in the manuscript, apart from those disclosed.

The views and opinions expressed in this article represent the personal ideas of the participants and are not necessarily official positions of the agency.

All authors except for B.H. Choi are employees of companies developing cellular therapies, providing testing, or enabling technologies for the manufacturing of cellular therapies.

\section{Acknowledgements}

We thank all other regulatory, academic and industrial participants who have not been listed directly. Additionally, we are grateful to those providing brief presentations on RM updates: Dr. Yoshitsugu Shitaka (FIRM), Dr. Tsui Yat Ping Alex (CMBA), Dr. Kum Cheun Wong (SAPI), Dr. Shinn-Zong Lin (BPIPO) and Dr. Yoji Sato (National Institute of Health Sciences) for presenting on WG2-related matters. We also thank the reviewers of this drafted text: Misaki Naota and Atsushi Nishikawa (PMDA), Wei-Chun Kan, Kun-Chin Ho, Fong-Chun Huang (Taiwan CDE), Kellathur Srinivasan (HSA), Seeun Kim (MFDS), V.G. Somani and Sanjeev Kumar (CDSCO). We thank Editage (www. editage.com) for English language editing.

\section{References}

[1] Yoneda T, Choi BH, Gupta PK, Ho C, Tsui YP, Wang L, et al. Nonclinical assessment of cell therapy products: the perspective from five Asian countries/regions based on regulatory guidelines and the underpinning rationales. Cytotherapy 2021;23 (10):874-85. https://doi.org/10.1016/j.jcyt.2021.04.007.

[2] Tanaka T, Lee SM, Mikami M, Yokota K, Takakura K. Gaps between Asian regulations for eligibility of human mesenchymal stromal cells as starting materials of cell therapy products and comparability of mesenchymal stromal cell-based products subject to changes in their manufacturing process. Regen Ther 2020;15:26573. https://doi.org/10.1016/j.reth.2020.10.004.

[3] Pharmaceuticals and Medical Devices Agency. Review Reports: Regenerative Medical Products, https://www.pmda.go.jp/english/review-services/reviews/approvedinformation/0004.html [accessed October 172021 ]. 